\title{
A novel ultrasonic tip for removal of filling material in flattened/oval-shaped root canals: a microCT study
}

\section{Melissa Esther RIVERA-PEÑA ${ }^{(a)}$ Marco Antônio Húngaro DUARTE(a) Murilo Priori ALCALDE ${ }^{(a)}$ Flaviana Bombarda DE ANDRADE(a) Rodrigo Ricci VIVAN(a)}

(a) Universidade de São Paulo - USP, Bauru School of Dentistry Department of Operative Dentistry, Endodontics and Dental Materials, Bauru, SP, Brazil.

Declaration of Interest: The authors certify that they have no commercial or associative interest that represents a conflict of interest in connection with the manuscript.

\section{Corresponding Author:}

Rodrigo Ricci Vivan

Email: rodrigo.vivan@fob.usp.br

htrps://doi.org/10.1590/1807-3107bor-2018.vol32.0088

Submitted: March 12, 2018

Accepted for publication: June 27, 2018

Last revision: July 17, 2018
Abstract: The aim of this study was to evaluate the influence of a novel ultrasonic tip as an auxiliary method for removing filling material from flattened/oval-shaped canals. The null hypothesis tested was that this method does not influence removing the filling material in flattened/ oval-shaped canals. Forty-five mandibular incisors were selected and randomly divided into three experimental groups $(n=15)$ according to different protocols for removing root canal filling material. Group R: Reciproc R25/.08, Group RC: Reciproc R25/.08 + Clearsonic tip, and Group CR: Clearsonic tip + Reciproc R25/.08. The teeth were scanned pre and post-operatively by means of a micro-computed tomography system. Data were analyzed using non-parametric Kruskal-Wallis and Dunn tests $(p<0.05)$. The percentage of residual root canal filling material between the experimental groups was examined. Statistically significant differences between the experimental groups were found in the root canal. Group R had the highest percentage of residual root canal filling material when compared with Groups RC and CR. The lowest percentage of residual root canal filling material was observed in Group CR. In the apical third of the root canal, statistically significant differences were found between the different protocols. The use of the ClearSonic tip followed by the Reciproc 25/.08 file to remove filling material resulted in the lowest percentage of residuals in the whole root canal and in the apical third.

Keywords: Endodontics; Ultrasonics; Retreatment; Dental Pulp Cavity; X-Ray Microtomography.

\section{Introduction}

Failure in endodontic treatment has been related to the presence of residual bacteria or secondary infections. ${ }^{1}$ In these cases, non-surgical retreatment should be considered the first and most conservative approach to improve prognosis..$^{1,2}$ Conventional endodontic treatment consists of cleaning, shaping, and filling the root canal system, offering a more favorable outcome when compared to endodontic surgery. ${ }^{2}$ Adequate removal of the endodontic filling material during retreatment procedures is essential to enhance the cleaning of the root canal system, avoiding the occurrence of reinfections and facilitating the healing of the periapical tissues. ${ }^{1,2}$ Different methods have been suggested for this purpose, including the use of heat, 
solvents, nickel-titanium (Ni-Ti) files, ultrasonic tips, or a combination of these techniques., ${ }^{3,45}$ The combined use of the dental operating microscope with specially designed ultrasonic tips has been recommended for endodontic retreatment procedures. ${ }^{3}$ The clarity and details of the magnified field can improve precision during gutta-percha removal. ${ }^{3}$

The Reciproc system (VDW, Munich, Germany), consisting of single-use reciprocating files, has also been indicated for retreatment purposes. ${ }^{5}$ According to some studies, ${ }^{2,6}$ reciprocating files have shown satisfactory results in retreatment procedures when used with a brushing motion against the root canal walls. Complete removal of filling materials should enable instruments and irrigating solutions to reach different areas of the root canal system. ${ }^{7}$ The achievement of patency and cleaning as near as possible to the apical region have been identified as prognostic factors related to periapical healing. ${ }^{7}$ For this reason, new protocols to reduce the residual of filling material during retreatment procedures should be studied.

Ultrasonic retreatment tips have been developed for removing filling material from the root canal walls, offering a promising outcome. ${ }^{3,4}$ Recently, a novel ultrasonic tip (Clearsonic, Helse Ultrasonic, Santa Rosa de Viterbo, Brazil) with an arrow-shaped section has been proposed as an auxiliary method for removing endodontic filling materials from flattened or ovalshaped canals. A literature search revealed that there are no previous studies about this novel ultrasonic tip. Thus, the purpose of this study was to evaluate the effect of a novel ultrasonic tip as an auxiliary method for removing filling material from oval/flattened root canals with the aid of the dental operating microscope (DOM) and micro-computed tomography $(\mu-\mathrm{CT})$ analysis. The null hypothesis was that the use of the Clearsonic tip does not affect the removal of filling material from flattened/oval-shaped canals.

\section{Methodology}

\section{Specimen selection}

The sample calculation was performed using the G*Power v3.1 for Mac (Heinrich Heine, Universität Düsseldorf) by selecting the one-way ANOVA fixed test. The data of a previous study with a similar number of samples were used ${ }^{8}$ and the effect size of the present study was established (0.65). The alpha (type I error) of 0.05 and a beta of 0.95 were also stipulated. A total of 14 specimens per group were indicated as the ideal size required for finding significant differences. An additional specimen per group was used to compensate possible loss while performing the experiments.

Forty-five mandibular incisors that were extracted from patients for reasons unrelated to this study were acquired after the Ethics Committee on Human Research approved the study (CEP 2.112.063). The samples were scanned before and after the procedures with a Skyscan 1174 micro-computed tomography system (Bruker-microCT, Kontich, Belgium). The parameters used were $50 \mathrm{kV}, 800 \mathrm{~mA}$, and a voxel size of $16.8-\mu \mathrm{m}$. The system included a charge-coupled device camera (1304_1024 pixels). Radiographic images of each sample were reconstructed by using the NRecon software (Bruker-microCT Kontich, Belgium). Three-dimensional models were reconstructed after the segmentation and binarization processes with the CTAn v.1.12 software (Bruker-microCT Kontich, Belgium). CTVol v.2.2.1 and Data Viewer software programs (Bruker-micro CT Kontich, Belgium) were used for visualizing and evaluating the internal anatomy. The teeth were selected according to a novel classification. ${ }^{9}$ Only ${ }^{1} \mathrm{TN}^{1}$ mandibular incisors with oval-shaped canals were selected. To be considered an oval-shaped canal, the bucco-lingual diameter had to be at least twice as wide as the mesio-distal diameter throughout the coronal two-thirds. ${ }^{10,11}$ Teeth with two root canals, an open apex, or with previous endodontic treatment were excluded.

During the experimental procedures, all the specimens were placed in a customized metallic muffle prepared for each specimen and fixed internally with silicone impression material to simulate clinical conditions. Access cavities were performed with a size 2 high-speed diamond bur (FG 1012 KG Sorensen, São Paulo, Brazil) under water spray. The working length was determined by placing a size $15 \mathrm{~K}$-file (Dentsply Maillefer, Ballaigues, Switzerland) into the canal until it was visible at the root apex under the dental operating microscope (Alliance Microscopia, São Carlos, Brazil), and was established at $1 \mathrm{~mm}$ short 
of this length. The samples $(\mathrm{N}=45)$ were randomly divided into three experimental groups according to the preparation technique. An endodontic specialist performed all the procedures at $6 \mathrm{x}$ magnification (Alliance Microscopia, São Carlos, Brazil).

\section{Shaping procedures}

Group PFCP: ProDesign Logic 25/.05 + Flatsonic (coronal and middle thirds) + Clearsonic (coronal and middle thirds) + Prodesign Logic 40/.01 $(n=15)$

A size $15 \mathrm{~K}$-file (Dentsply Maillefer, Ballaigues, Switzerland) was passively inserted up to the working length of the root canal. The ProDesign Logic 25/.05 instrument was operated in rotating motion powered by a torque-limited electric motor (Easy Equipamentos Odontológicos, Belo Horizonte, Brazil) at $950 \mathrm{rpm}$ and $4 \mathrm{~N} / \mathrm{cm}$ torque in accordance with the manufacturer's instructions. The instrument was introduced into the root canal until resistance was felt, and a brushing motion within a 3-mm amplitude limit was applied three times. Subsequently, the instrument was removed and cleaned, and the root canal was irrigated with 3 $\mathrm{mL}$ of $1 \%$ sodium hypochlorite $(\mathrm{NaOCl})$. This sequence was repeated until $2 / 3$ of the working length was reached. An ultrasonic tip with a flattened arrowshaped design (Flatsonic, Helse Ultrasonic, Santa Rosa do Viterbo, Brazil) mounted in an ultrasonic device (NSK Brasil Ldta, São Paulo, Brazil) at a frequency of $30 \mathrm{kHz}$ was used. The tip was activated for three cycles of 20 seconds in the buccal-lingual direction with the purpose of touching these walls. The protocol for this procedure, determined after a pilot study, was repeated three times, and after each cycle, $3 \mathrm{~mL}$ of $1 \% \mathrm{NaOCl}$ was used for irrigation. Another ultrasonic tip with a convex arrow-shaped design (Clearsonic) was used, applying the same protocol for ultrasonic instrumentation of the root canal as previously described. The ProDesign Logic $40 / .01$ instrument was operated at $350 \mathrm{rpm}$ and $1 \mathrm{~N} /$ $\mathrm{cm}$ torque in accordance with the manufacturer's instructions and under the experimental conditions described for the use of these rotary files. Afterwards, the instrument was removed and cleaned and the root canal was irrigated as described above. This sequence was repeated until reaching the working length of the root canal.
Group FCP: Flatsonic (coronal and middle thirds) + Clearsonic (coronal and middle thirds) + ProDesign Logic 40/.01 ( $n=15)$

A size 15 K-file (Dentsply Maillefer, Ballaigues, Switzerland) was passively inserted into the working length of the root canals. Afterwards, these instruments were used under the same experimental conditions as described in Group PFCP.

Group (PP): Prodesign Logic 25/.05 +

Prodesign Logic 40/.05 ( $n=15)$

A size 15 K-file (Dentsply Maillefer, Ballaigues, Switzerland) was passively inserted into the working length of the root canals. The ProDesign Logic 25/.05 instrument was operated in rotating motion powered by a torque-limited electric motor (Easy Equipamentos Odontológicos, Belo Horizonte, Minas Gerais, Brazil) at $950 \mathrm{rpm}$ and $4 \mathrm{~N} / \mathrm{cm}$ torque in accordance with the manufacturer's instructions. The instrument was introduced into the root canal until resistance was felt and a brushing motion within a $3 \mathrm{~mm}$ amplitude limit was applied three times. Subsequently, the instrument was removed and cleaned and the root canal was irrigated with $3 \mathrm{~mL}$ of $1 \%$ sodium hypochlorite $(\mathrm{NaOCl})$. This sequence was repeated until the working length was reached. Afterwards, the ProDesign Logic 40/.05 instrument was operated in the same manner as the ProDesign Logic 25/.05 instrument. Subsequently, the instrument was removed and cleaned and the root canal was irrigated as described above. This sequence was repeated until the working length was reached.

\section{Root canal filling procedures}

Subsequently, a final irrigation protocol was used, consisting of $2 \mathrm{~mL}$ of refreshed $2.5 \% \mathrm{NaOCl}$, ultrasonically activated with an ultrasonic device (NSK) using an Irrisonic tip (size 20, 0.01 taper) (Helse Ultrasonic, Santa Rosa do Viterbo, Brazil) set to low power, three times for 20 seconds each. The specimens were flushed with $17 \%$ EDTA for 3 minutes and ultrasonically activated for 60 seconds. The root canals were flushed with $2 \mathrm{~mL}$ of $2.5 \% \mathrm{NaOCl}$ and ultrasonically activated three times for 20 seconds. ${ }^{12}$ The specimens were finally rinsed with saline solution, and then dried with sterile paper points. Afterwards, 
the samples were scanned using the standardized parameters previously mentioned.

Root canals were filled by the continuous wave of condensation technique, using a size $25 / .04$ or 40/.04 master gutta-percha points (Dentsply Tulsa Dental Specialties, Tulsa, Oklahoma, USA) according to the instrumentation protocol applied. An epoxy resin-based sealer, Sealer Plus (MK Life, Porto Alegre, Brazil), was used in all groups. ${ }^{13,14}$ A FF or MF (depending on the master cone size) heat carrier tip (Friendo, Endo Apex, Dentazon Corporation, Gyeonggi-do, Korea) set at $170^{\circ} \mathrm{C}$ was inserted 5 $\mathrm{mm}$ from the working length and activated for 10 seconds. After this, it was reactivated for 1 second and removed from the canal. ${ }^{6}$ The middle and coronal portions of the root canals were filled with Gutta Easy, (Endo Apex, Dentazon Corporation, Gyeonggi-do, Korea) at a temperature of $180^{\circ} \mathrm{C}$ and compacted with compatible Shilder pluggers (Dentsply Maillefer. Ballaigues, Switzerland). The specimens were temporarily restored with Cavit (3M ESPE, Seefeld, Germany) and then stored at $100 \%$ humidity at $37^{\circ} \mathrm{C}$ for 30 days to allow complete setting of the sealer before the micro-computed tomography scans.

\section{Micro-computed tomographic analysis}

The CTAn software (v.1.12, Bruker-microCT) was used for measuring the volume of radiopaque filling material $\left(\mathrm{mm}^{3}\right)$ and the presence of residual filling material was calculated as a percentage. ${ }^{11}$ Qualitative two-dimensional and three-dimensional analysis of residuals in the total root canal and apical portion of the canal were assessed on cross-sectional images and 3D models by using the CTAn (v.1.12, BrukermicroCT) and CTVol (v.2.3.1, Bruker-microCT) software programs.

\section{Filling removal technique}

The filling removal procedures were performed with the use of a dental operating microscope (Alliance Microscopia, São Carlos, Brazil) at 6x magnification. The specimens were randomly divided into three groups according to the filling removal technique.

\section{Group R: Reciproc R25/.08 ( $n=15$ )}

In this group, the Reciproc R25 instrument was used with the VDW Silver motor in an in-and-out pecking motion until the working length was reached, using the RECIPROC ALL mode. Subsequently, a brushing motion was applied until no residual filling material was visible under the DOM. A single operator performed all filling removal procedures. One drop $(0.8 \mathrm{~mL})$ of xylene solvent was placed in the pulp chamber for 1 minute before starting the removal procedure. The root canals were irrigated with $1 \% \mathrm{NaOCl}$. The specimens were scanned using the parameters previously described, by means of a Skyscan 1174 micro-computed tomography system (Bruker-microCT, Kontich, Belgium).

\section{Group RC: Reciproc R25/.08 + Clearsonic ( $n=15)$}

The Reciproc R25 instrument was used under the same experimental conditions as described for the specimens in Group R Thus, an ultrasonic tip with an arrow-shaped design R1 Clearsonic (Figure 1) mounted in an ultrasonic device (NSK) at a frequency of $30 \mathrm{kHz}$ was used. The device was activated for six cycles of 20 seconds in the bucco-lingual direction using an in-and-out pecking motion with the purpose of removing the filling material from the coronal and middle thirds of the root canal for a total of 2 minutes. The root canals were irrigated with $1 \% \mathrm{NaOCl}$. The specimens were scanned for the last time.

\section{Group CR: Clearsonic + Reciproc R25/.08 ( $n=15)$}

Firstly, the Clearsonic ultrasonic tip was used to remove the filling material, following the same protocol applied for the specimens in Group RC. The Reciproc R25 instrument was used under the same experimental conditions as previously described. The root canals were irrigated with $1 \% \mathrm{NaOCl}$ and the specimens were scanned for the last time.

\section{Statistical analysis}

For data analysis, the Graph Pad Prism 6 (GraphPad Software, Inc., California, USA) software was used. The non-parametric Kruskal-Wallis and Dunn tests 


\section{A}

\section{B}
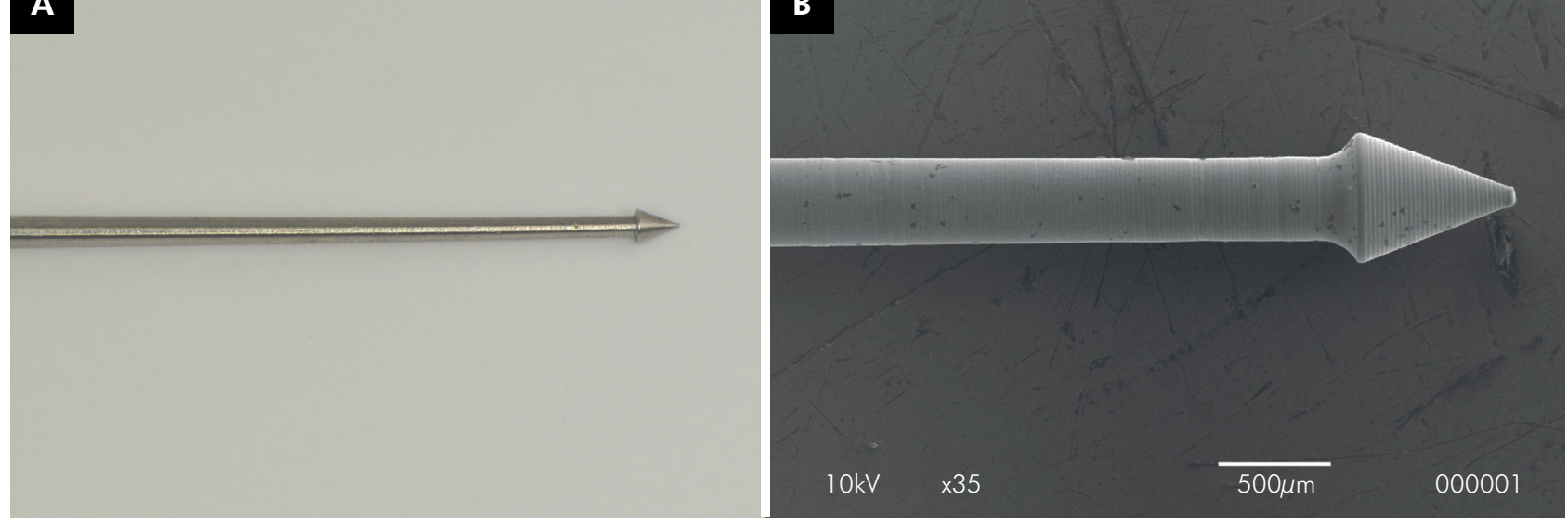

Figure 1. (A) Ultrasonic Clearsonic tip and (B) micro-computed tomography image of the Clearsonic tip (original magnification, 35x).

were performed due to the presence of non-normal distribution according to the Shapiro-Wilk's test. The significance level was $5 \%$.

\section{Results}

The percentage of residual root canal filling material in the total root canal presented statistically significant differences between Groups R and RC ( $p$ $<0.05$; Table 1; Figure 2). Similarly, Group R differed from group $\mathrm{CR}(\mathrm{p}<0.05$; Table 1; Figure 2) showing significant differences. Group R showed the highest percentage of residuals (76\%) when compared with Groups RC (24\%) and CR (16\%), which had the lowest percentage of residuals. Concerning the percentage of residuals in the apical third of the root canal, statistically significant differences were found when Group R (86\%) and RC (100\%) were compared with Group CR (21\%). The technique used in Group CR showed the lowest percentage of residuals $(p<0.05$; Table; Figure 2).

\section{Discussion}

Failure in endodontic treatment has been associated to the presence of residual bacteria or reinfection of endodontically treated teeth because of inadequate cleaning, disinfection, shaping or filling of the root canals. ${ }^{11}$ The objective of endodontic retreatment is the removal of the contaminated filling material ${ }^{15}$ and bacterial remnants from the root canal space. ${ }^{10}$ the
Table. Percentages of residual filling material (median, minimum-maximum) at the whole root canal and apical third.

\begin{tabular}{lcc}
\hline Group & Total & Apical 1/3 \\
\hline$R(\%)$ & $76.10(2.800-99.40)^{a}$ & $86.70(0.0-100.0)^{a}$ \\
RC (\%) & $24.80(6.500-86.00)^{b}$ & $100.0(81.40-100.0)^{a}$ \\
CR (\%) & $16.20(3.500-48.00)^{b}$ & $21.90(0.0-93.20)^{b}$ \\
\hline
\end{tabular}

Different letters in each column indicates statistically significant difference $(p<0.05)$.

present study, the efficacy of different protocols for removing filling material from oval/flattened root canals with the aid of a dental operating microscope (DOM) was assessed by $\mu$-CT. The use of engine-driven instruments, convenient for retreatment procedures due to their agility and safety, minimizes both operator and patient fatigue. ${ }^{2}$ Oval canals were selected for this study because removing the filling material from these teeth is a challenging procedure. ${ }^{6,10,11}$ Therefore, the use of ultrasonic technology for the removal of filling material in the coronal and middle thirds, ${ }^{16}$ as well as the DOM, have been recommended during endodontic retreatment. ${ }^{1}$

Studies have reported that none of the existing systems removes all the residual filling material from the root canal space. ${ }^{6}$ Therefore, xylene was used as a solvent to facilitate the removal of guttapercha due to its efficient dissolving action. ${ }^{4,17}$ However, practitioners may encounter difficulties during retreatment procedures even with the aid of magnification and ultrasound. ${ }^{6,15} \mu$-CT imaging is a 


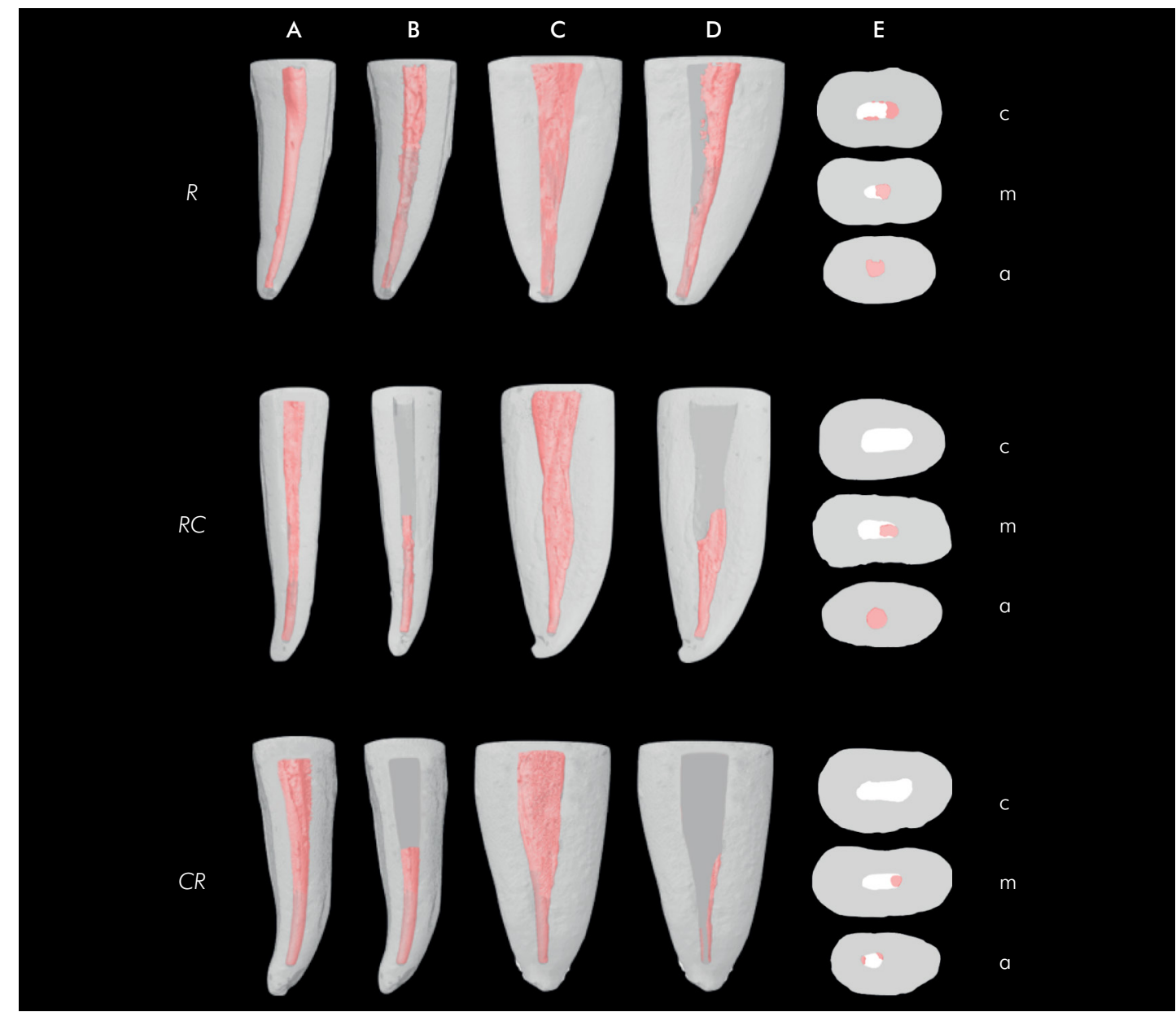

Figure 2. Representative reconstructions of the superimposed specimens before (A and $C$ ) and after (B and $D)$ removing the filling material in each experimental group. Front ( $A$ and $B)$ and side views ( $C$ and $D)$. Representative cross-sections of the superimposed flattened/oval-shaped mandibular incisors (E) after removing the filling material in each experimental group at the coronal (c), middle (m), and apical (a) thirds.

non-invasive and reproducible method that allows the development of accurate three-dimensional models and acquisition of quantitative data without destroying the samples. ${ }^{18,19,20}$. This technology is considered ideal for quantifying the volume of filling material before and after its removal. ${ }^{11,17}$

The null hypothesis that there is no significant difference between the protocols used for the removal of filling material was rejected. The results of this study revealed that none of the protocols was able to completely remove the filling material in flattened/oval-shaped canals. Consequently, residual filling material was found in all specimens. Relative to the percentage of residues in the total root canal, Group R showed the highest percentage (76\%) when compared with Groups RC (24\%) and CR (16\%). This suggested that the use of Reciproc 25/.08 alone was insufficient to promote a substantial reduction in the percentage of filling material residuals in flattened/oval-shaped canals, possibly due to the difficulties related to the anatomy of these teeth. Otherwise, the lowest percentage of residuals was found in Group CR. In the apical third of the root canal, Group R $(86 \%)$ and RC (100\%) had higher percentages of residuals than Group CR $(21 \%)$, which showed the lowest percentage. According to these results, the use of ClearSonic was the most effective method for removing the filling material from the coronal and middle thirds, and Reciproc $25 / .08$, was the most effective in the total canal 
and apical third of the oval-shaped canals. These results were in agreement with those of a previous study, in which use of the DOM associated with an ultrasonic tip for endodontic retreatment improved the removal of filling material compared with the control group without the use of this technology. ${ }^{3}$ Increased visualization of a properly illuminated field plays an important role during the procedure. ${ }^{3}$ However, the use of an ultrasonic instrument is essential to dislodge the filling material, promoted by the cutting effect of low piezoelectric oscillation. ${ }^{3}$ The use of hybrid techniques and larger preparation diameters may enhance the cleanliness of the root canal walls. ${ }^{7}$ However, filling material removal depends on preoperative factors, such as root canal morphology, filling materials, and size and diameter of the prepared canal. ${ }^{7}$ The use of different instrumentation protocols might have affected the results and is a limitation of our study.

A study by Kasam and Mariswamy ${ }^{4}$ described the use of an ultrasonic tip for the retreatment of mandibular premolars. The authors explained that the ultrasonic tip removed material from the root canals within a short time and produced little extrusion. The ultrasonic vibration promoted the displacement of the filling material from the root canal walls by enhancing sealer removal. ${ }^{4}$ The frictional heat produced by the ultrasonic instrument causes a synergistic effect on gutta-percha, leading to its softening and displacement from the root canal. ${ }^{4}$ In the same study, ${ }^{4}$ the authors showed that the best results for removing filling material were observed in the coronal (6\%) and middle (7\%) thirds of the canal compared with the apical third (14\%), due to the tip diameter (0.06) that was too large to reach the apical third. Similarly, the protocols used in our study left a higher percentage of filling material in the apical third. These results could be explained by the diameter of the ClearSonic ultrasonic tip, which corresponds to an ISO size 50 file $(0.5 \mathrm{~mm})$, restricting its access to the apical third of the root canal. Crozeta et al. ${ }^{11}$ reported a $43 \%$ of residual filling material in the total canal and $70 \%$ in the apical third of oval-shaped canals prepared with Reciproc 50/.05. In this case, a size 50 file was considered the ideal instrument for preparing ovalshaped distal canals of mandibular molars. These results were due to the reciprocating motion that induce the instrument to progressively move forward and push debris toward the apex.11,21 Therefore, the higher percentages of residual filling material in the apical third was also expected in the present study.

On the other hand, Bernardes et $a .^{10}$ studied the amount of residual filling material in flattened canals after using different techniques with or without ultrasonic activation of irrigants. Specimens treated with ultrasonically activated irrigants and the Reciproc 50/.05 file showed $1.6 \%$ of residual filling material, similar to the use of Reciproc alone (4\%). The efficiency of the Reciproc file for removing the filling materials has been described in previous studies that used circular or curved canals. 1,2, 5,10,15,17

To the best of our knowledge, this is the first study to assess the influence of this novel ultrasonic tip compared with the Reciproc 25/.08 file for removing the filling material in flattened or oval-shaped mandibular incisors. This was achieved by using the Reciproc 25/.08 file alone or associating this instrument with the Clearsonic tip to test the efficacy of this protocol considering the anatomy of the specimens. However, the authors did not examine the ability of the instruments to re-prepare the oval-shaped root canals.

\section{Conclusion}

Within the limitations of this laboratory study, the null hypothesis that a novel ultrasonic tip does not influence the removal of filling material was rejected. The presence of residual filling material was observed in the oval/flattened root canals, irrespective of the protocol used. The use of the Clearsonic tip before the Reciproc 25/.08 file provided the lowest percentage of residual filling material in the total canal and apical third of the root canals.

\section{Acknowledgments}

The authors deny any conflict of interest. 


\section{References}

1. Rios MA, Villela AM, Cunha RS, Velasco RC, De Martin AS, Kato AS et al. Efficacy of 2 reciprocating systems compared with a rotary retreatment system for gutta-percha removal. J Endod. 2014 Apr;40(4):543-6. https://doi.org/10.1016/i.joen.2013.11.013

2. Rodrigues CT, Duarte MA, Almeida MM, Andrade FB, Bernardineli N. Efficacy of $\mathrm{cm}$-wire, $\mathrm{m}$-wire, and nickel-titanium instruments for removing filling material from curved root canals: a micro-computed tomography study. J Endod. 2016 Nov;42(11):1651-5. https://doi.org/10.1016/i.joen.2016.08.012

3. Mello Junior JE, Cunha RS, Bueno CE, Zuolo ML. Retreatment efficacy of gutta-percha removal using a clinical microscope and ultrasonic instruments: part I-an ex vivo study. Oral Surg Oral Med Oral Pathol Oral Radiol Endod. 2009;108(1):e5962. https://doi.org/10.1016/i.tripleo.2009.03.027

4. Kasam S, Mariswamy AB. Efficacy of different methods for removing root canal filling material in retreatment-an in-vitro study. J Clin Diagn Res. 2016 Jun;10(6):ZC06-10. https://doi. org/10.7860/JCDR/2016/17395.7904

5. Özyürek T, Demiryürek EÖ. Efficacy of different nickeltitanium instruments in removing gutta-percha during root canal retreatment. J Endod. 2016 Apr;42(4):646-9. https:// doi.org/10.1016/i.joen.2016.01.007

6. Zuolo AS, Zuolo ML, Bueno CES, Chu R, Cunha RS. Evaluation of the efficacy of TRUShape and reciproc file systems in the removal of filling material: an ex vivo microcomputed tomographic study. J Endod. 2016 Feb;42(2):315-9. https://doi.org/10.1016/i.joen.2015.11.005

7. Rossi-Fedele G, Ahmed HM. Assessment of root canal filling removal effectiveness using micro-computed tomography: a systematic review. J Endod. 2017 Apr;43(4):520-6. https://doi.org/10.1016/i.joen.2016.12.008

8. Rödig T, Kupis J, Konietschke F, Dullin C, Drebenstedt S, Hülsmann M. Comparison of hand and rotary instrumentation for removing gutta-percha from previously treated curved root canals: a microcomputed tomography study. Int Endod J. 2014 Feb;47(2):173-82. https://doi.org/10.1111/iej.12128

9. Ahmed HM, Versiani MA, De-Deus G, Dummer PM. A new system for classifying root and root canal morphology. Int Endod J. 2017 Aug;50(8):761-70. https://doi.org/10.1111/iej.12685

10. Bernardes RA, Duarte MA, Vivan RR, Alcalde MP, Vasconcelos $B C$, Bramante CM. Comparison of three retreatment techniques with ultrasonic activation in flattened canals using micro-computed tomography and scanning electron microscopy. Int Endod J. 2016 Sep;49(9):890-7. https://doi.org/10.1111/iej.12522

11. Crozeta BM, Silva-Sousa YT, Leoni GB, Mazzi-Chaves JF, Fantinato T, Baratto-Filho F et al. Micro computed tomography study of filling material removal from oval-shaped canals by using rotary, reciprocating and adaptive motion systems. J Endod. 2016 May;42(5):793-7. https://doi.org/10.1016/i.joen.2016.02.005

12. Sluis LW, Vogels MP, Verhaagen B, Macedo R, Wesselink PR. Study on the influence of refreshment/activation cycles and irrigants on mechanical cleaning efficiency during ultrasonic activation of the irrigant. J Endod. 2010 Apr;36(4):737-40. https://doi.org/10.1016/i.joen.2009.12.004

13. Cintra LT, Benetti F, Queiroz IOA, Ferreira LL, Massunari L, Bueno $\mathrm{CR}$ et al. Evaluation of the Cytotoxicity and Biocompatibility of New Resin Epoxy-based Endodontic Sealer Containing Calcium Hydroxide. J Endod. 2017 Dec;43(12):2088-92. https://doi. org/10.1016/i.joen.2017.07.016

14. Vertuan GC, Duarte MA, Moraes IG, Piazza B, Vasconcelos $B C$, Alcalde MP et al. Evaluation of physicochemical properties of a new root canal sealer. J Endod. 2018 Mar;44(3):501-5. https://doi.org/10.1016/i.joen.2017.09.017

15. Zuolo AS, Mello Junior JE, Cunha RS, Zuolo ML, Bueno CE. Efficacy of reciprocating and rotary techniques for removing filling material during root canal retreatment. Int Endod J. 2013 Oct;46(10):947-53. https://doi.org/10.1111/iej.12085

16. Hess D, Solomon E, Spears R, He J. Retreatability of a bioceramic root canal sealing material. J Endod. 2011 Nov;37(11):1547-9. https://doi.org/10.1016/i.joen.2011.08.016

17. Fruchi LC, Ordinola-Zapata R, Cavenago BC, Hungaro Duarte $M A$, Bueno CE, De Martin AS. Efficacy of reciprocating instruments for removing filling material in curved canals obturated with a singlecone technique: a micro-computed tomographic analysis. J Endod. 2014 Jul;40(7):1000-4. https://doi.org/10.1016/i.joen.2013.12.011

18. Rhodes JS, Ford TR, Lynch JA, Liepins PJ, Curtis RV. Microcomputed tomography: a new tool for experimental endodontology. Int Endod J. 1999 May;32(3):165-70. https://doi.org/10.1046/j.1365-2591.1999.00204.x

19. Peters OA, Laib A, Rüegsegger P, Barbakow F. Threedimensional analysis of root canal geometry by high-resolution computed tomography. J Dent Res. 2000 Jun;79(6):1405-9. https://doi.org/10.1177/00220345000790060901

20. Versiani MA, Ordinola-Zapata R, Keleş A, Alcin H, Bramante CM, Pécora JD et al. Middle mesial canals in mandibular first molars: A micro-CT study in different populations. Arch Oral Biol. 2016 Jan;61:130-7. https://doi.org/10.1016/j.archoralbio.2015.10.020

21. Lu Y, Wang R, Zhang L, Li HL, Zheng QH, Zhou XD et al. Apically extruded debris and irrigant with two $\mathrm{Ni}$-Ti systems and hand files when removing root fillings: a laboratory study. Int Endod J. 2013 Dec;46(12):1125-30. https://doi.org/10.1111/iej.12104 